The Journal of Animal \& Plant Sciences, 31(1): 2021, Page: 77-85

ISSN (print): 1018-7081; ISSN (online): 2309-8694

\title{
COMPARATIVE IN VIVO EFFICACY OF ORAL FORMULATIONS OF IVERMECTIN AND LEVAMISOLE AGAINST NATURAL HELMINTH INFECTION IN SMALL RUMINANTS
}

\author{
S. Ahmad ${ }^{1}$, M. S. Sajid ${ }^{* 1,2}$, R. Tabassum ${ }^{3}$, R. M. Siddique ${ }^{4}$, M. Imran ${ }^{1}$ and M. A. Malik ${ }^{1}$ \\ ${ }^{1}$ Department of Parasitology, University of Agriculture, Faisalabad-38040, Pakistan, ${ }^{2}$ Center for Advanced Studies in \\ Agriculture and Food Security (CAS-AFS), University of Agriculture, Faisalabad, Pakistan, ${ }^{3}$ Department of Livestock \\ and Dairy Development (L\&DD), Punjab, Pakistan, ${ }^{4}$ Department of Pathobiology, Riphah College of Veterinary \\ Science, Riphah International University Islamabad, Lahore Campus, Pakistan. \\ *Corresponding Author's e-mail: drsohailuaf@hotmail.com
}

\begin{abstract}
This study was conducted to investigate the distribution of gastrointestinal (GI) parasites and their control in sheep and goats of the three villages of Faisalabad, Pakistan. Faecal samples ( $\mathrm{n}=347$ each) were analyzed through McMaster egg counting technique. The comparative efficacy of the oral formulations of ivermectin (KEPROMAC ORAL ${ }^{\circledR}$ Holland) and levamisole (Nilverm ${ }^{\circledR}$ Pakistan) was evaluated at the recommended doses. Faecal samples were obtained directly from the recta at $1^{\text {st }}, 7^{\text {th }}, 14^{\text {th }}$ and $21^{\text {st }}$ day after treatment. The overall prevalence of the GI parasites was $81.27 \%$ in sheep and $54.47 \%$ in goats. Intrinsic determinants like age, sex and breed were found significantly $(\mathrm{P} \leq 0.05)$ associated. Among various husbandry practices; grazing, hygienic conditions, housing systems, floor pattern and animal keeping system have shown significant effects $(\mathrm{P} \leq 0.05)$. The post treatment Faecal Egg Count Reduction Test (FECRT) indicated reduction of eggs up to day 14 followed by increase at $21^{\text {st }}$ day in both species. The efficacy of ivermectin was higher as compared to levamisole-treated group. However, the treated groups indicated significant reduction as compared to untreated control. The study provided the better choice of drug for preventive and/or therapeutic management of GI parasitism in sheep and goat populations of the selected villages of Faisalabad district, Punjab, Pakistan.
\end{abstract}

Key words: Gastrointestinal parasitism, sheep, goat, epidemiology, anthelmintic efficacy; intrinsic determinants.

https://doi.org/10.36899/JAPS.2021.1.0195

Published online August 26, 2020

\section{INTRODUCTION}

Sheep and goats are playing an important role in uplifting the Pakistan's economy in terms of value addition in the gross domestic product of Pakistan. Small ruminants are greatly affected by Gastrointestinal (GI) parasites particularly helminths (Sevinç et al., 2004); broadly classified as into orders Nematoda, Trematoda and Cestoda. They affect the health of animals badly thus causing huge economic losses. Helminths harm the animals by affecting at subclinical and clinical levels (Ng'ang'a et al., 2004; Khan et al., 2017). Haemonchosis and fasciolosis are the major diseases which cause voluminous economic losses on the basis of reproductive inefficiency, decreased weight and mortality (Iqbal et al., 2007; Khan et al., 2010 2011; 2013; Rizwan et al., 2016; Ahmad et al., 2017). Former is responsible for 26 M US\$ annually losses in sheep and goat industry in Kenya while later resulted into $48.8 \mathrm{M}$ Ethiopian Birr losses per year in Ethiopian highlands (Mukhebi et al., 1985; Ngategize et al., 1993). The economic losses due to haemonchosis in terms of productive and reproductive inefficiency have been reported worldwide including $\$ 436$ million in Australia (Emery et al., 2016), \$26 million in Kenya
(Elemo and Geresu, 2017), \$ 46 million in South Africa (Jeremiah and Banwo, 2019) and \$ 103 million in India (Prakash et al., 2018).

In Pakistan, it has been observed that the treatment cost of haemonchosis was of worth Rs. 25 million/ annum. Moreover, due to decreased milk yield (134062.39 million/ annum), weight gain (40 million/ annum) and in terms of mortality (142902 million/ annually) losses have been observed (Qamar et al., 2011; Qasim et al., 2016; Ahmad et al., 2020). GI parasites reduce the profitability up to $15 \%$ and cause weight losses up to $50 \%$ in Pakistan and these parasites cause lower quality wool and meat in sheep and goat industry which causes huge economic losses estimated around 19.7 $\mathrm{M}$ and $31.4 \mathrm{M}$ per year due to lower quality wool and meat production in Faisalabad (Hussain, 1985).

A number of diverse methods are being used to control helminths in sheep and goats; including biological, management, immunological and chemical methods. Amongst these, the chemical control has remained a corner-stone around the globe because of its convenience; this method is cheap, simple and easy to handle and provides both prophylactic and therapeutic cover against helminths (Hussain et al., 2011). Nevertheless, anthelmintics created a problem of 
resistance of helminths globally against themselves due to their prophylactic use (Jackson and Miller, 2006). Due to emergence of anthelmintic resistance and availability of handful of anthelmintic compounds, the mass preventive therapeutic approaches are not gaining significance (Tinkler, 2020). In Pakistan, helminths are being treated by different broad-spectrum anthelmintics like levemisole and ivermectin (Zaman et al., 2017). Levamisole is used orally while ivermectin is in injectable form. Moreover, ivermectin is usually considered more effective against ectoparasites. They develop resistance against anthelmintics, if they are used over and over again. Moreover, ivermectin has usually been considered more effective against ectoparasites and no use of oral ivermectin has been observed against GI parasites in Pakistan (Ahmad et al., 2020). In this study, the prevalence of GI parasites and in vivo comparative efficacies of oral ivermectin and levamisole have been observed for the first time in the three villages of selected study district. The study will help in adding up the data regarding prevalence of GI parasites and development of anthemintic resistance in existing bank of knowledge. Moreover, it will help the field veterinarians in updating their treatment regime against GI parasites.

\section{MATERIALS AND METHODS}

Study Area: This study was carried out in sheep and goat populations of the three villages viz; 227 Chadhar, 227 Karar wala and 209 RB of Faisalabad, Punjab, Pakistan. The district Faisalabad is situated between latitude $30^{\circ} 31.5$ North and $73^{\circ} 74$ east, about 184 meters above the sea level, covering the area of $1,230 \mathrm{~km}^{2}$. The district is surrounded by the cities of Chiniot, Jhang, Okara, Sahiwal, Sheikhupura and Gojra. There are five Tehsils (administrative sub-divisions) in Faisalabad district including Sadar, Samundri, Jaranwala, Chak Jhumra and Tandlianwala.

Questionnaire-Based Passive Surveillance: A predesigned questionnaire containing open and closed ended questions was developed for the passive surveillance of GI parasitic infection of goat and sheep population. Information about the goat and sheep breeds including age, sex, housing system, feeding system and watering system was recorded. Formal and informal testing procedures were used to test the questionnaire as suggested by Thrusfield et al. (2018). Livestock and Dairy Development Department, Punjab (L\&DD) determined the outbreak of GI parasitic infection in these three villages of district Faisalabad, Pakistan. Sheep and goats $(n=347)$ each in these villages were selected. Sampling was done through convenient sampling method (Thrusfield et al., 2018) from the sheep and goats that approached the veterinary camps organized by the L\&DD in collaboration with the Department of Parasitology,
Faculty of Veterinary Science, University of Agriculture, Faisalabad (UAF), Punjab, Pakistan.

Faecal examination: Faecal samples of sheep and goats were collected directly from the recta and stored in plastic bottles labeled with all the necessary information. They were carried in refrigerated vials to the Department of Parasitology, UAF for further processing and examination. The quantitative faecal examination was done using McMaster egg counting technique and eggs per gram of faeces were determined. Briefly, three grams of the faecal material was mixed in $42 \mathrm{~mL}$ of water. After mixing, the suspension was sieved (through $0.15 \mathrm{~mm}$ aperture) and centrifuged the filtrate at $300 \times g$ for two minutes. After centrifugation, the sediment was separated and tube was refilled with the saturated salt solution $(\mathrm{NaCl})$. After mixing of sediment with salt solution, the chambers of McMaster were filled and observed for the counting of eggs. The eggs of different parasites were also identified on the basis of their morphology (Soulsby, 1982).

Faecal Egg Count Reduction Test (FECRT): Total animals (sheep and goats each) were virtually divided into three equal sub groups (A, B, and $\mathrm{C}$ ) as per randomized complete block design. Sub group A was administered with the oral ivermectin (Kepromac Oral ${ }^{\circledR}$ Holland) with the dose rate of $0.2 \mathrm{mg} / \mathrm{kg}$, group B was orally administered with the levamisole (Nilverm ${ }^{\circledR}$ Pakistan) with the dose rate of $5 \mathrm{mg} / \mathrm{kg}$ and group $\mathrm{C}$ was kept as an untreated control group. Faecal samples of these selected animals were extracted after treatment. Faecal egg counts were performed at $1^{\text {st }}, 7^{\text {th }}, 14^{\text {th }}$ and $21^{\text {st }}$ days after application of the anthelmintics to determine their comparative efficacy as per the formula given earlier by Ali (2001). The trials were conducted as per the guidelines given by the the World Associateion for the Advancement of Veteirnary Parasitology (WAAVP) (Coles et al., 1992).

Statistical analyses: Prevalence of GI parasites in sheep and goats and comparative efficacy of different anthelmintics was analyzed by chi-square and ANOVA respectively at $95 \%$ confidence level (Schork and Remington, 2010). The statistical analysis was performed using SAS software package (SAS, 2010).

\section{RESULTS}

Overall prevalence of the GI parasitism in small ruminant populations of the selective villages of Faisalabad was found as $67.87 \%$ (471/694). Among the different species screened, GI parasitism was found significantly higher $(\mathrm{P} \leq 0.05 ; \mathrm{OR}=1.94)$ in the sheep $81.27 \% \quad(282 / 347)$ than goats $54.47 \% \quad(189 / 347)$. Nematodes were found significantly higher $(\mathrm{P} \leq 0.05)$ as compared to other GI parasites in both sheep and goats. 
In case of breeds of sheep, highest prevalence was found in Kajli followed in order by Thalli and Lohi showing significant association $(\mathrm{P} \leq 0.05 ; \mathrm{OR}=2.41)$ between GI parasites prevalence and breed of sheep. Among goat breeds, highest prevalence was found in non-descript breed $(\mathrm{OR}=3.06)$ followed in order by Beetal and Teddy (2.85). A significant association $(\mathrm{P} \leq 0.05)$ was observed between prevalence of GI helminths and study breeds of goat.

Higher prevalence of GI parasites was found in young animals $(\mathrm{P} \leq 0.05)$ than adults. Each breed of sheep and goats had higher $(\mathrm{P} \leq 0.05 ; \mathrm{OR}=1.54)$ GI parasitic occurrence in youngstock than adults. Results are significantly associated In case of gender of the sheep and goats, higher prevalence was found in females than males in all the study breeds. Results are significantly associated $(\mathrm{P} \leq 0.05 ; \mathrm{OR}=1.47)$ between prevalence of $\mathrm{GI}$ parasites and gender of the study breeds.

Sheep and goat populations of district Faisalabad are offered with the two types of feeding viz; grazing on the fields and stall feeding at the farm or house. We observed higher prevalence of GI parasites in grazing animals followed by stall-fed $(\mathrm{P} \leq 0.05$; $\mathrm{OR}=1.49)$. There were different hygienic conditions in different farms/ herds/ households where small ruminants were kept. Prevalence of GI helminths was significantly higher $(\mathrm{P} \leq 0.05 ; \mathrm{OR}=3.02)$ in poor and fair hygienic conditions $(\mathrm{P} \leq 0.05 ; \mathrm{OR}=2.40)$ as compared to good hygienic conditions. In study villages of Faisalabad, open, semiclosed and closed systems of housing are usually adopted for rearing of the small ruminants. GI parasitism was significantly higher $(\mathrm{P} \leq 0.05 ; \mathrm{OR}=2.89)$ in open and semiclosed $(\mathrm{P} \leq 0.05 ; \mathrm{OR}=2.41)$ as compared to closed housing system in sheep and goats as revealed.

In the study area, the three types of floor patterns viz; cemented, un-cemented and partiallycemented were reported to be used for rearing of small ruminants. Higher prevalence was found in animals kept on un-cemented floor $(\mathrm{P} \leq 0.05 ; \mathrm{OR}=3.63)$ and partiallycemented floor $(\mathrm{P} \leq 0.05 ; \mathrm{OR}=2.68)$ as compared to animals houses of cemented floors. In study area, different watering systems were used for watering of small ruminants. They were watered by canal, tape and ponds. The results showed no significant association $(\mathrm{P}>$ 0.05; OR=1.09) in both sheep and goat. Two levels of the animal keeping were studied viz; open-placed animals and tethered animals. As far as the association of animal keeping with the prevalence of GI helminths is concerned, higher prevalence was found in open placed animals as compared to rope tied animals. Results are significantly associated $(\mathrm{P} \leq 0.05 ; \mathrm{OR}=1.64)$ between prevalence of GI parasites and animal keeping.

Both oral ivermectin and levamisol showed significant effects against GI parasites. However, oral ivermectin showed better anthelmintic efficacy against GI parasites at all days of treatment than levamisol. Fig. 1 represents the comparative efficacy of oral ivermectin and levamisol as compared to untreated control in sheep and goat populations of study area.

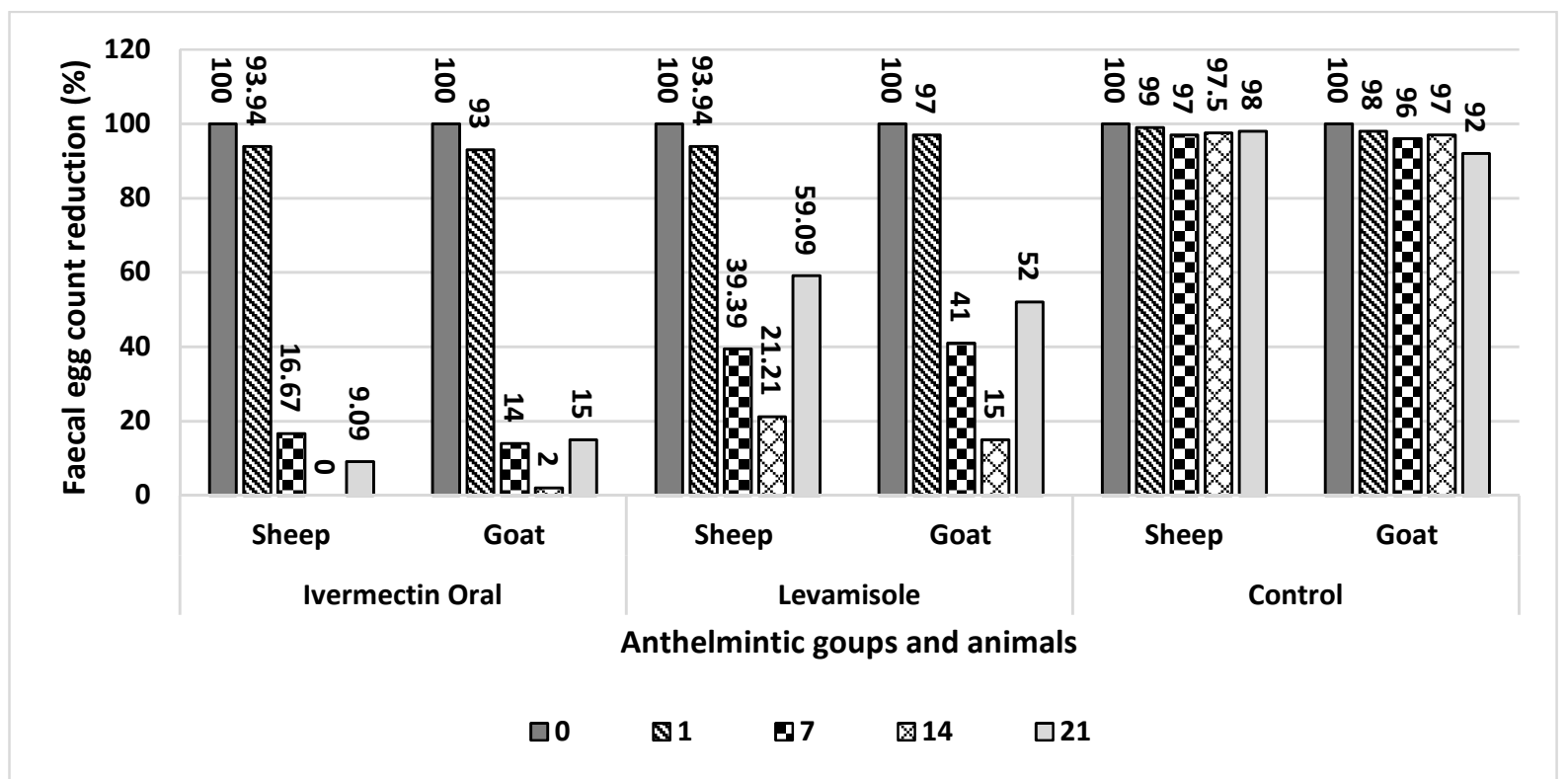

Figure 1. Comparative efficacy of oral ivermectin and levamisole in sheep and goat population of selected villages of Sadar, Faisalabad, Pakistan. 


\section{DISCUSSION}

Anthelmintic resistance has coined its worth in the parasite control program due to natural process of selection of resistant parasites in around a decade's period (Køhler, 2001; Gilleard and Beech, 2007). Hence, periodic monitoring of the efficacy of various anthelmintic compounds is required in order to provide an effective control strategy to the livestock farmers and small ruminant herdsmen to get optimum productivity and avoid wastage of resources in Pakistan (Jabbar et al., 2008) as well as other parts of the world (Ihler, 2010; Shalaby, 2013; Zanzani et al., 2014; Lambertz et al., 2019). Due to lack of awareness and increased ratio of quackery lead to inappropriate use of drugs which in turn resulted in development of resistance along with residual effects in milk, meat and other by-products (Tsiboukis et al., 2013). Among various alternative strategies, use of various pharmacokinetic-based approaches with an objective of increasing the parasitic exposure (Lanusse et al., 2018), various combinations of drugs, using alternative approaches (bioactive compounds) like tannins (Iqbal et al., 2007), ethnobotanicals (Hussain et al., 2008; 2011), phytotherapeutic approaches (Razzaq et al., 2019), and mineral supplementation strategies (Qudoos et al., 2017; Rizwan et al., 2019; Ahmad et al., 2020) have been adapted as useful tools to attain sustainability in parasitic control.

The present study determines the distribution of GI parasites among sheep and goat populations of selective villages of district Faisalabad. Reported species of helminths in current study are previously reported by Siddiqi and Ashraf (1980), Mohiuddin et al. (1984), Khan et al. (1989), Raza et al. (2007; 2014), Farooq et al. (2012), and Nabi et al. (2014) from different parts of Pakistan and Pandey et al. (1994), Mohanta et al. (2007), Lone et al. (2012), Elshahawy et al. (2014), Emery et al. (2016) and Mork et al. (2019) reported worldwide. However, these workers have also described some other helminths in addition to those documented in the current study. Variations also occur in the rate of prevalence of changed helminths in different regions. Such a regional variation in the record of numerous species has been extensively reported. A variety of factors like breed of the host, age, grazing habits, economic capacity of the farmers, level of education, sex, anthelmintic used and standard of management (Komoin et al., 1999; Ouattara and Dorchies, 2001) can influence the existence of helminths species (Ahmad et al., 2020).

Similar results of nematodal infection have also been reported by Opara et al. (2005), Raza et al. (2007), and Zeryehun (2012) from different parts of world. In an autopsy of a dead Anatolian wild sheep, a bunch of helminthes including Thysaniezia ovilla from cestodes, Coenurus cerebralis and Cysticercus taenuicollis from larvae cestode, Cystocaulus ocreatus, Marshallagia (M.) marchalli, Ostertagia (O.) circumcincta, O. occidentalis, Nematodirus sp., Chabertia ovina from nematodes were found and reported for the first time by Sevinç et al. (2004). Other helminths identified from the faecal examination of other animals in the herd included eggs of Trichostrongylus sp., Nematodirus sp., M. marshalli, and Trichuris sp.; larvae of Dictyocaulus filaria and Cystocaulus ocreatus; and oocysts of Eimeria sp. In a recent investigation in Chakwal district, GI parasitic fauna of the grazing sheep included $H$. contortus, $O$. trifurcata, Trichostrongylus spp., Strongyloides papillosus, M. marshalli, Avitellina centripunctata, Fasciola (F.) gigantica and F. hepatica (Qudoos et al., 2017), In Sialkot district, the GI parasites included: $F$. hepatica, F. gigantica, H. contortus, Eimeria crandallis, Trichostrongylus sp. (Rizwan et al., 2017; 2019), Gongylonema pulchrum (Rizwan et al., 2017), Oesophagostomum sp., Trichuris ovis, Strongyloides sp. Cryptosporidium sp. (Rizwan et al., 2019). In two ecologies viz; Ziarat, Baluchistan and Talagang, Punjab, a recent investigation revealed distribution of Haemonchus, Trichuris, Strongyloides and Trichostrongylus parasites among the sheep and goat population (Razzaq et al., 2019). The moderate prevalence of trematodes in sheep and goats in the present study may be attributed to the low frequency of intermediate hosts. Also, the fasciolosis mainly belongs to marshy areas of the country i.e. near the rivers and canals. Present study area has not swampy environment which leads to low prevalence of trematodes as compared to nematodes. The low prevalence of cestodes in goats was due to adequate non-availability of intermediate host (Soulsby, 1982; Elemo and Geresu, 2017). This may also be due to the climatic conditions in the study area.

In the same study district, different results were recorded by Khan (1985). It was concluded that $54.4 \%$ goats were infected with GI helminths and the highest prevalence were in the month of August. Pal and Qayyum (1992) reported that kaghani breed of goat is more susceptible to GI helminths as compared to other local breeds of goats. Raza et al. (2007) reported 52\% of the goats are infected with GI helminths in Southern Punjab, Pakistan. Asif et al. (2008) found $63.70 \%$ rate of infection of the GI parasites in sheep population of Rawalpindi and Islamabad and in the same area Gadahi et al. (2009) report that $66.45 \%$ of the small ruminants are infected GI parasites. Over all 39\% prevalence was recorded by Farooq et al. (2012) in the desert of Cholistan but in the same area Raza et al. (2014) reported $78.2 \%$ sheep population was infected with GI helminths. This great variation in results may be due to climatic changes in the area. Mehmood et al. (2013) reported that the overall prevalence of GI helminths in sheep and goat population of Lahore was $67.08 \%$. Recently, GI parasitism in the grazing sheep has been reported as $32.6 \%$ and $32.81 \%$ in Sialkot district (Rizwan et al., 
2017; 2019) and 42.44\% in Multan district (Ahmad et al., 2020).

Sheep and goat raising methods may play crucial role in high nematode infection in the present study among the small ruminants. Pastures/fields are important source of nematodes infective third stage larvae and sheep and goats may become highly infective by grazing these pastures. Other contributing factor in high nematode prevalence as compared to trematods and cestodes may the development of anthelmintic resistance (Emery et al., 2016). Other thing is that most of the nematodes possess direct life cycle i.e. no involvement of intermediate host definitely ensures the high prevalence of nematodes (Gulland and Fox, 1992; Mork et al., 2019). The environment of the study area is favorable for the optimum development and survival of infective larval stages of the nematodes.

Influence of gender on the prevalence of GI helminths is quite controversial as some researchers report higher prevalence in female animals and some reported that male animals have more rate of infection in sheep and goats. Previously, Pal and Qayyum (1992) reported higher prevalence in female $(89.94 \%)$ as compared to male goats $(78.57 \%)$. So the results of current study are in line with Pal and Qayyum (1992) investigations. Raza et al. (2007) also reported the same results as female sheep have high rate of infection as compared to male animals. Nabi et al. (2014) reported different result as he concluded that male animals (46.66\%) have more rate of infection to nematodes as compared to female animals (34.66\%). Raza et al. (2014) and Qasim et al. (2016) also reported that male animals $(81.10 \%)$ have more rate of infection to nematodes as compared to female animals $(77.30 \%)$.

Raza et al. (2007) reported that young goats have high rate of infection as compared to adults. Also, higher prevalence in young and immature goats $(48 \%)$ as compared to adults (26\%) is reported by Nabi et al. (2014) in district Swat. The lower age groups of animals found to be more infected with GI helminth parasites in sheep and goats is because of the high susceptibility and low resistance in young animals (Sheikh et al., 2016). Hence, age and immunity level of the host both play important role in the onset of parasitic infection. The decreased burden of parasites or parasitemia in adults shows that the immunity has been developed due to consistent exposure of the host to parasitic infection (Jeremiah and Banwo, 2019). As the animals or the host passes specific age (one year in animals) it become resistant to most of parasitic infections while, some of the parasites requires continuous exposure to maintain their resistant level in the body of the host (Vlassoff et al., 2001). Other extrinsic factors such as feeding system, floor pattern, animal keeping and housing system greatly influence the prevalence of GI helminthiasis in sheep and goats. Current study revealed that animal facing grazing, open housing and un-cemented floor pattern have more rate of infection as compared to stall feeding, semi close housing and cemented floor pattern, respectively (Emery et al., 2016).

Body weight gain was not influenced by these administered anthelmintics in the present study. A normal weight gain trend was observed. Some previous studies revealed a significant gaining of body weight by sheep and goats after administration of anthelmintics (Zajac et al., 1992; Umur et al., 1993; Hannan et al., 2001; Islam et al., 2003). This difference in weight gain might be due to size of observational periods. The present study was part of an ongoing campaign of the Livestock and Dairy Development Department and was limited to post treatment observational time period of not more than 21 days.

There are five altered chemical groups which are being used in broad-spectrum anthelmintics viz; imidazothiazoles, benzimidazoles, macrocyclic lactones and spiroindoles. Benzimidazoles contain thiabendazole, fenbendazole, albendazole, oxfendazole and probenzimedazole which are precursors of new broadspectrum antiparasitics. Much effectiveness is shown by these compounds against numerous GIT parasites and larvae. Imadozothiazoles contain morantel, pyrental and levemisole. These are broad-spectrum anthelmintics with much efficacy and results. Macrocyclic lactones contain milbemycin and avermectins which are administered by injection or pour-on method. These are extremely effective against larva and adults of endoparasites (Ratnaparhki et al., 1992).

Effectiveness of ivermectin against GI parasites resembled with the results of previous studies (Kashai et al., 1984; Gupta et al., 1989; Ratnaparhki et al., 1992 and Mahbub, 1996). That study has shown $89.5 \%-100 \%$ effectiveness against endoparasites in sheep and goats in different regions of world (Stevenson et al., 2002; Mork et al., 2019). The efficacy of ivermectin in the present study has been reported significantly higher $(\mathrm{P} \leq 0.05)$ as compared to levamisole as the infection rate of GI helminths decreased up to $2 \%$ at $14^{\text {th }}$ day of administration of ivermectin while at the same time the infection rate was $13 \%$ by administration of levamisole. This shows that the ivermectin is more effective as compared to levamisole. Number of different factors like sample size, preparation of drugs, dose rates, route used for direction of drug and degree of endoparasitic infection might cause slight deviations of results of the efficiency of ivermectin (Afaq, 2003; Babar, 2005; Saddiqi, 2005; Saeed et al., 2007; Qamar et al., 2011; Qasim et al., 2016; Bibi et al., 2017; Parakash et al., 2018). Though, efficiency of ivermectin in this study certainly proved no contrary effects. Oral formulation of ivermectin has not so for been evaluated which can give a better alternate of the available formulations for controlling GI parasites in small ruminant population of the study district. Other 
formulations of ivermectin Endectin, Ivotek, Vermectin and Wormec are different formulations of different companies having ivermectin and Nilworm, Nilzan, Levasel Sol., Levasel Bol., Vernil, Levoton and Nawazan are different formulation of levamisole (Mahbub, 1996; Stevenson et al., 2002; Sevinç et al., 2004) which can be used in Pakistan for control of GI parasites.

Benzimidazoles have not been found to cause genetic diversity in $H$. contortus as determined through microsatellites-based markers (Chaudhry et al., 2016). In a recent comparative efficacy trial of various anthelmintics viz; macrocyclic lactones, benzimidazoles and other drug combinations against natural infections of GI helminthes in 8 goat flocks of Italy, FECRT posttreatment with benzimidazoles showed better results as compared to macrocyclic lactones, salicylanilide, imidathiazole and various combinations (Lambertz et al., 2019). Identified parasites included larvae of Haemonchus sp., Trichostrongylus sp., and Teladorsagia sp. In a recent anthelmintic efficacy trial conducted in the sheep and goat populations, no resistance has been reported against levamisole, levamisole-oxfendazole combination and ivermectin treatment against natural GI parasitic infection in the selected herds of Baluchistan and Punjab, Pakistan (Razzaq et al., 2019). Identified parasitic fauna included: Haemonchus sp., Trichuris sp., Strongyloides sp., and Trichostrongylus sp. No identification of parasites pre or post treatment with the study drugs was conducted in our investigation due to paucity of time and limited resources.

Conclusions: During the present study, it is concluded that GI parasitism is among the major threats and primary constraints to the sheep and goat productivity in Faisalabad. Among different parasites, nematodes are the most prevalent helminthes than trematodes and cestodes; Haemonchus contortus being the main culprit. Current study revealed that younger animals, females, grazing system, open housing and un-cemented floor pattern are positively associated with the rate of helminthosis as compared to males, stall fed, semi-closed housing and cemented floor pattern, respectively. Both the treated groups indicated significant reduction in the faecal egg counts (FEC) as compared to un-treated control; however, an oral forumulation of ivermectin provided significantly higher reduction in FEC than levamisol in sheep and goat population of the study district.

\section{REFERENCES}

Afaq, M. (2003). Parasitic control practices and anthelmintic resistance against GIT nematodes of Sheep. PhD thesis, Department of Vet. Parasitol., Univ. Agri., Faisalabad, Pakistan.
Ahmad M., M.N. Khan, M.S. Sajid, G. Muhammad, A. Qudoos, and H.M. Rizwan (2017). Prevalence, economic analysis and chemotherapeutic control of small ruminants fasciolosis in the Sargodha district of Punjab, Pakistan. Vet. Ital. 53: 47-53.

Ahmad, S., M.S. Sajid, M.K. Khan, R. Nadeem, H.M. Rizwan, M.A. Malik, and F. Yosuf (2020). Effect of trace element supplementation on the gastrointestinal parasites of grazing sheep. The J. Anim. Plant Sci. 30: 72-80

Ali, M.M. (2001). A synopsis of epidemiology and basic statistics. $2^{\text {nd }}$ Edi. Iftikhar book Co. Tipu Rd. Opp. R.M.C. Rawalpindi, Pakistan. p. 37.

Asif, M., S. Azeem, S. Asif, and S. Nazir (2008). Prevalence of gastrointestinal parasites of sheep and goats in and around Rawalpindi and Islamabad, Pakistan. J. Vet. Anim. Sci. 1: 14-17.

Babar, W. (2005). Worm control practices and anthelmintic resistance in nematodes of sheep and goats at livestock farm Jaba and its surroundings (NWFP). MSc thesis, Deptt. of Vet. Parasitol., Univ. Agri., Faisalabad, Pakistan.

Bibi, R., K. Afshan, I.A. Khan, Z. Iqbal, A.R. Kayani, M. Mushtaq, M. Irfan, M. Qayyum and M.F. Hassan (2017). Phenotyping and Prevalence of Haemonchus contortus (Nematoda: Trichostongylidae) in Ruminants from Endemic Areas of Pakistan: Influence of Host Species and Geographical Area on Phenotypic Traits of Worms. Pakistan Vet. J. 37: 170-174.

Chaudhry, U., E.M. Redman, K. Ashraf, M.Z. Shabbir, M.I. Rashid, S. Ashraf and J.S. Gilleard (2016). Microsatellite marker analysis of Haemonchus contortus populations from Pakistan suggests that frequent benzimidazole drug treatment does not result in a reduction of overall genetic diversity. Parasit. Vectors. 9: 349.

Coles, G.C., C. Bauer, F.H. Borgsteede, S. Geerts, T.R. Klei, M.A. Taylor, P.J. Waller (1992). World Association for the Advancement of Veterinary Parasitology (W.A.A.V.P.) methods for the detection of anthelmintic resistance in nematodes of veterinary importance. Vet. Parasitol. 44: 35-44.

Elemo, K.K and M.A. Geresu (2017). Prevalence and risk factors of gastro intestinal parasites of small ruminants in Sinana and Dinsho districts of Bale Zone, South Eastern Ethiopia. European J. Biol. Sci. 9: 1-8.

Elshahawy, I.S., A.M. Metwally, and D.A. Ibrahim (2014). An abattoir-based study on helminthes of slaughtered goats (Capra hircus L., 1758) in Upper Egypt, Egy. Helminthol. 51: 67-72.

Emery, D.L., P.W. Hunt and L.F. Le Jambre (2016). Haemonchus contortus: the then and now, and 
where to from here?. Int. J. Parasitol. 46: 755769.

Farooq, Z., S. Mushtaq, Z. Iqbal, and S. Akhtar (2012). Parasitic helminths of domesticated and wild ruminants in Cholistan desert of Pakistan. Intl. J. Agric. Biol. 14: 63-68.

Gadahi, J.A., M.J. Arshed, Q. Ali, S.B. Javaid, and S.I. Shah (2009). Prevalence of gastrointestinal parasites of sheep and goat in and around Rawalpindi and Islamabad, Pakistan. Vet. World. 2: 51-53.

Gilleard, J.S., and N. Beech (2007). Population genetics of anthelmintic resistance in parasitic nematodes. Parasitol. 134: 1133-1147.

Gulland, F.M.D., and M. Fox (1992). Epidemiology of nematode infections of Soay sheep (Ovis aries L.) on St Kilda. Vet. Parasitol. 105: 481-492.

Gupta, S.C., R. Chandra, and S.C. Yadav (1989). Efficacy of triclabendazole against experimental Fasciola gigantica infection in sheep, goat, buffalo and rabbit: a comparative study. Indian Vet. J. 66: 680-682.

Hannan, A.S.M.A., M. Mostofa, M.A. Hoque, and M.A. Alim (2001). Efficacy of ivomec pour-on against gastrointestinal nematodes, lice and ticks in goats. Bang. Vet. J. 18: 95-98.

Hussain, A., M.N. Khan, Z. Iqbal, and M.S. Sajid (2008). An account of the botanical anthelmintics used in traditional veterinary practices in Sahiwal district of Punjab, Pakistan, J. Ethnopharmacol. 119: 185-190.

Hussain, A., M.N. Khan, Z. Iqbal, M.S. Sajid, M.K. Khan (2011). Anthelmintic activity of Trianthema portulacastrum L. and Musa paradisiaca L. against gastrointestinal nematodes of sheep. Vet. Parasitol. 179: 92-99.

Hussain, Q. (1985). Studies on the incidence of gastrointestinal parasites and efficacy of Banmnth-II against nematodes in buffalo calves. M.Sc. Thesis, Univ. Agri., Faisalabad, Pakistan.

Ihler, C.F. (2010). Anthelmintic resistance: an overview of the situation in the Nordic countries. Acta Vet. Scand. 52: S1-S24.

Iqbal, M.U., M.S. Sajid, A. Hussain, and M.K. Khan (2007). Prevalence of helminth infections in dairy animals of Nestle milk collection areas of Punjab (Pakistan). Italian J. Anim. Sci. 6: 935938.

Iqbal, Z., M. Sarwar, A. Jabbar, S. Ahmed, M. Nisa, M.S. Sajid, M.N. Khan, K.A. Mufti, M. Yaseen (2007). Direct and indirect anthelmintic effects of condensed tannins in sheep. Vet. Parasitol. 144: 125-131.

Islam, M.S. (2003). Comparative efficacy of Endokill, Vermic, Ralnex, Deminth and Levanid against gastrointestinal nematodiasis and effects on blood parameters in buffaloes. M.Sc. Thesis. Bangladesh Agricultural University, Mymensingh, Bangladesh.

Jabbar A, Z. Iqbal, H.A. Saddiqi, W. Babar, M. Saeed (2008). Prevalence of multiple anthelmintic resistant gastrointestinal nematodes in dairy goats in a desolated tract (Pakistan). Parasitol Res. 103: 29-35.

Jackson, F., and J. Miller (2006). Alternative approaches to control-Quo vadit? Louisiana State Uni. Baton Rouge, USA. Vet. Parasitol. 139: 371384.

Jeremiah, O.T. and O.G. Banwo (2019). Haematologic profile and prevalence survey of haemonchosis in various breeds of slaughtered cattle in Ibadan, Nigeria. Nigerian J. Anim. Prod. 46: 151-162.

Kashai, T., P. Redl, R. Farkas, E. Fok, L. Pap, K. Takach, and T. Kassai (1984). Studies on the effi cacy of ivermectin against endo and ecto parasites in cattle and pigs. Veterinarna Sbirka. 82: 33-37.

Khan, M.K., M.S. Sajid, H. Riaz, N.E. Ahmad, L. He, M. Shahzad, A. Hussain, M.N. Khan, Z. Iqbal, J.L. Zhao (2013). The global burden of fasciolosis in domestic animals with Lan outlook on the contribution of new approaches for the diagnosis and control. Parasitol. Res. 112: 2421-2430.

Khan, M.K., M.S. Sajid, M.N. Khan, Z. Iqbal, M. Arshad, A. Hussain (2011). Point prevalence of bovine fascioliasis and the influence of chemotherapy on the milk yield in a lactating bovine population from the district of Toba Tek Singh, Pakistan. J. Helminthol. 85: 334-338.

Khan, M.N. (1985). A survey of gastrointestinal helminthiasis and study of the taxonomy of the species of genus Ostertigia in sheep and goats. M.Sc. Thesis, Department of Vet. Parasitol. Faculty of Veterinary Science, Univ. Agric., Faisalabad, Pakistan.

Khan, M.N., C.S. Hayat, A.H. Chaudhry, Z. Iqbal, and B. Hayat (1989). Prevalence of gastrointestinal helminths in sheep and goats at Faisalabad abattoir. Pakistan Vet. J. 9: 159-161.

Khan, M.N., M.S. Sajid, H.M. Rizwan, A. Qudoos, R.Z. Abbas, M. Riaz and M.K. Khan (2017). Comparative efficacy of six anthelmintic treatments against natural infection of fasciola species in sheep. Pakistan Vet. J. 37: 65-68.

Khan, M.N., M.S. Sajid, M.K. Khan, Z. Iqbal and A. Hussain (2010). Gastrointestinal helminthiasis: prevalence and associated determinants in domestic ruminants of district Toba Tek Singh, Punjab, Pakistan. Parasitol. Res. 107: 787-794.

Køhler, P. (2001). The biochemical basis of anthelmintic action and resistance. Intl. J. Parasitol. 31: 336345 . 
Komoin, O.C., J. Zinsstag, V.S. Pandey, F. Fofana, and A.N. Depo (1999). Epidemiology of parasites of sheep in the southern forest zone of Coted'Ivoire. Revued'Elevage- et-de-MedecineVeterinairedes- Pays-Tropicaux. 52: 39-46.

Lambertz, C., I. Poulopoulou, K. Wuthijaree, and M. Gauly (2019). Anthelmintic efficacy against gastrointestinal nematodes in goats raised under mountain farming conditions in northern Italy, BMC Vet. Res. 15: 216.

Lanusse, C., C. Canton, G. Virkel, L. Alvarez, L. CostaJunior, and A. Lifschitz (2018). Strategies to optimize the efficacy of anthelmintic drugs in ruminants, Trends Parasitol. 34: 664-682.

Lone, B.A., M.Z. Chishti, F. Ahmad, and H. Tak (2012). A survey of gastrointestinal helminth parasites of slaughtered sheep and goats in Ganderbal, Kashmir. G. V. 8: 338-341.

Mahbub, A. (1996). Anthelmintic efficacy against fascioliasis and gastrointestinal nematodiasis with haemato-biochemical changes in sheep and goats. M.Sc. Thesis. Bangladesh Agricultural University, Mymensingh, Bangladesh.

Mehmood, K., M. Ijaz, A.Z. Durrani, M.A. Khan, A.J. Sabir, and M.H. Saleem (2013). Infection rate and therapeutic trials on various gastrointestinal parasites in sheep and goats in and around Lahore, Pakistan. Pakistan J. Zool. 45: 489-494.

Mohanta, U., K. Anisuzzaman, T. Farjana, P.M. Das, S. Majumder, and M.M.H. Mondal (2007). Prevalence, population dynamics and pathological effects of intestinal helminths in black Bengal goats. Bangl. J. Vet. Med. 5: 6369.

Mohiuddin, A., N.M. Khan, F.A. Mughal, and M.A. Sheikh (1984). Taxonomy, incidence and seasonal variations of helminth parasites of sheep and goats of Sind, Pakistan. Pakistan J. Zool.16: 25-30.

Mørk, T., R.A. Ims and S.T. Killengreen (2019). Rodent population cycle as a determinant of gastrointestinal nematode abundance in a lowarctic population of the red fox. Int. J. Parasitol. Parasites Wildl. 9: 36-41.

Mukhebi, A., R.S. Shavolemo, F. Ruvuna, and F. Rurangirwa (1985). Economics on internal parasitic control among goats in western Kenya. Proceedings of the 4th Small Ruminant Collaborative Support Program (SR-CRSP) ScientificWorkshop. ILRAD, Nairobi, Kenya, March, 1985.

Nabi, H., K. Saeed, S.R. Shah, M.I. Rashid, H. Akbar, and W. Shehzad (2014). Epidimiological study of gastrointestinal nematodes of goats in district
Swat, Khyber pakhtunkhwa, Pakistan. Sci. Int. 26: 283-286.

Nganga, C.J., N. Maingi, P.W.N. Kanyari, and W.K. Munyua (2004). Development, survival and availability of gastrointestinal nematodes of sheep on pastures in a semi-arid area of Kajiado District of Kenya. Vet. Res. Com. 28: 491-501.

Ngategize, P.K., T. Bekele, and G. Tilahun (1993). The financial losses caused by ovine fascioliosis in the Ethiopian highlands. Trop. Anim. Health Pro. 25: 155-161.

Opara, M.N., J.K. Nwaobasi, and I.C. Okoli (2005). Occurrence of parasitic helminths among small ruminants reared under traditional husbandry system in Owerri, south east Nigeria. Bull Anim. Health Prod. Africa. 53: 226-233.

Ouattara, L., and P. Dorchies (2001). Gastrointestinal helminths of sheep and goats in subhumid and sahelian areas of Burkina Faso. Rev. Med. Vet. 152: $165-170$.

Pal, R.A., and M. Qayyum (1992). Distribution of gastrointestinal helminths of goats in Swat Valley (NWFP), Pakistan. Pakistan J. Zool. 24: 359-360.

Pandey, V.S., M. Ndao, and V. Kumar (1994). Seasonal prevalence of gastrointestinal nematodes in communal land goats from the highveld of Zimbabwe. Vet. Parasitol. 51: 241-248.

Prakash, O., S. Gomathinayagam, T.J. Harikrishnan, M. Raman, V. Pandiyan and S. Saho (2018). Haemonchus contortus load and anthelmintics resistance in Sheep and Goats in Chennai, Tamil Nadu, India. Int. J Chem. Studies. 6: 2712-2716.

Qamar, M.F., A. Maqbool and N. Ahmad (2011). Economic losses due to haemonchosis in sheep and goats. Sci. Intern. 23: 321-4.

Qasim, H.M., M. Avais, A.Z. Durrani, M.A. Khan and A.H. Shahzad (2016). Dynamic dispersal of haemonchosis, its treatment and effect on blood profile of small ruminants of Lodhran District, Punjab, Pakistan. Pakistan J. Zool. 48: 755-761.

Qudoos, A., M.N. Khan, M.S. Sajid, and G. Muhammad (2017). Correlation of trace mineral profiles with gastrointestinal worm burden in rangeland sheep of Chakwal district, Punjab, Pakistan. Intl. J. Agric. Biol. 19: 140-144.

Ratnaparhki, M.R., U.V. Shastri, B.W. Narlandkar, S.U. Digraskar, and N.M. Degloorkar (1992). A note on efficacy of some flukicides against Fasciola infection in domestic animals. Ind. J. Vet. Med. 12: 20

Raza, M.A., M. Younas, and E. Schlecht (2014). Prevalence of gastrointestinal helminths in pastoral sheep and goat flocks in the Cholistan desert of Pakistan. J. Anim. Plant Sci. 24: 127134. 
Raza, M.A., Z. Iqbal, A. Jabbar, and M. Yaseen (2007). Point prevalence of gastrointestinal helminthiasis in ruminants in southern Punjab, Pakistan. J. Helminthol. 81: 323-328.

Razzaq A., I. Muhammad, Z. Islam. Z. Fatima, M. Hussain, and Farmanullah (2019). Monitoring anthelmintics resistance and assessing effectiveness of herbal anthelmintics against small ruminants' nematodes infection in Pakistan, Pakistan J. Agric. Res. 32: 662-669.

Rizwan, H.M., M.S. Sajid, M.N. Khan, and M. Saqib, (2016). Seroepidemiology of goat fascioliasis in district Sargodha, Punjab, Pakistan based on excretory secretory antigens of the indigenous strains of Fasciola gigantica. Rev. de Med. Vet. 167 (1-2): 10-17.

Rizwan, H.M., M.S. Sajid, Z. Iqbal, and M. Saqib (2019). Association of phytomineral with gastrointestinal parasites of grazing sheep in Sialkot district, Punjab, Pakistan. Pakistan J. Agri. Sci. 56: 459-468.

Rizwan, H.M., M.S. Sajid, Z. Iqbal, and M. Saqib (2019). Point prevalence of gastrointestinal parasites of domestic sheep (Ovis aries) in district Sialkot, Punjab, Pakistan. The J. Anim. Plant Sci. 27: 803-808.

Saddiqi H.A. (2005). Benzimidazole resistance and associated contributing factors in gastrointestinal nematodes of sheep and goats. M.Sc. (Hons.) Thesis., Deptt. of Veterinary Parasitol., Univ. Agri., Faisalabad, Pakistan.

Saeed M., Z. Iqbal, and A Jabbar (2007). Oxfendazole resistance in gastrointestinal nematodes of Beetal goats at livestock farms of Punjab, Pakistan. Acta Vet. Brno. 76: 79-85.

SAS. 2010. SAS/STAT User Guides version 6.12. SAS Inst Inc, Cary, NC, USA.

Schork, M.A. and R.D. Remington (2010). Statistics with Applications to the Biological and Health Sciences, $3^{\text {rd }}$ Ed., Lexington, KY, USA.

Sevinç, F., F. Güçlü, and U. Uslu (2004). Anadolu Yaban Koyununda (Ovis orientalis anatolica) Bulunan Parazitler, Erciyes Üniv. Vet. Fak. Derg., 2: 8789.

Shalaby, A.H. (2013). Anthelmintics resistance; how to overcome it? Iranian J. Parasitol. 8: 18-32.

Sheikh B.A., F. Ahmad and T.A. Sofi (2016). Seasonal Prevalence of Gastro-Intestinal Helminths of Sheep (Ovis aries) and Goat (Capra hircus) with Respect to Age and Gender of Gurez Valley, Kashmir. J. Anim. Sci. Adv. 6: 1609-1625.
Siddiqi, M.N., and M. Ashraf (1980). Helminthiasis in goats slaughtered in the abattoirs of Peshawar, NWFP. Pakistan J. Agric. Res. 1: 64-74.

Soulsby, E.J.L. (1982). Helminths, arthropods and protozoa of domesticated animals. $7^{\text {th }} \mathrm{Ed}$. Bailliere Tindal and Cassel Ltd. London, UK.

Stevenson, C.R., R.H. Mahoney, P. Fisara, G. Strehlau, and M.P. Reichel (2002). The efficacy of formulation of triclabendazole and ivermectin in combination against liver fluke (Fasciola hepatica) and gastrointestinal nematodes in cattle and sheep and sucking lice in cattle. Aust. Vet. J. 80: 698-701.

Thrusfield, M., R. Christley, H. Brown, P.J. Diggle, N. French, K. Howe, L. Kelly, A. O'Connor, J. Sargeant and H. Wood (2018). Veterinary Epidemiology. $4^{\text {th }}$ Ed. John Wiley and Sons Ltd., West Sussex, UK.

Tinkler, S.H. (2020). Preventive chemotherapy and anthelmintic resistance of soil-transmitted helminths - Can we learn nothing from veterinary medicine? One Health. 9: 100-106.

Tsiboukis, D., E. Sazakli, E. Jelastopulu, M. Leotsinidis (2013). Anthelmintics residues in raw milk. Assessing intake by a children population. Pol. J. Vet. Sci. 16: 85-91.

Umur, S., and K. Irmak (1993). Treatment of natural sarcoptic mange in sheep with ivermectin and Phoxim. Ankara Üniversitesi Veteriner Fakültesi Dergisi. 40: 301-310.

Vlassoff, A., D.M. Leathwick and A.C. Heath (2001). The epidemiology of nematode infections of sheep. N. Z. Vet. J. 49: 213-221.

Zajac, A.M., C.D. Thatcher, R.A. Brook, S.H. Umberger, and D.R. Notter (1992). Comparison of ivermectin formulations in an ovine parasite control programme. Vet. Rec. 130: 333-354.

Zaman, M.A., I. Zafar, Z.U. Sindhu, R.Z. Abbas and M.F. Qamar (2017). An overview of plants with acaricidal and anthelmintic properties. Int. J. Agri. Biol. 19: 957-968.

Zanzani, S., A. Gazzonis, A. Di Cerbo, M. Varady, M. Manfredi (2014). Gastrointestinal nematodes of dairy goats, anthelmintic resistance and practices of parasite control in northern Italy. BMC Vet Res. 10: 114

Zeryehun, T. (2012). Helminthosis of sheep and goats in and around Haramaya, southeastern Ethiopia. J. Vet. Med. Anim. Health. 4: 48-55. 